\title{
Laboreal
}

Volume $13 \mathrm{~N}^{\circ} 1$ | 2017

Varia

\section{A aptidão profissional segundo J.-M. Lahy}

La aptitud profesional según J.-M. Lahy

L'aptitude professionnelle selon J.-M. Lahy

The occupational skill according to J.-M. Lahy

\section{Marcel Turbiaux}

Tradutor. João Viana Jorge

\section{OpenEdition}

\section{Journals}

\section{Edição electrónica}

URL: http://journals.openedition.org/laboreal/802

DOI: $10.4000 /$ laboreal. 802

ISSN: 1646-5237

\section{Editora}

Universidade do Porto

\section{Refêrencia eletrónica}

Marcel Turbiaux, «A aptidão profissional segundo J.-M. Lahy », Laboreal [Online], Volume $13 \mathrm{~N}^{0} 1$

2017, posto online no dia 01 julho 2017, consultado o 24 setembro 2020. URL : http://

journals.openedition.org/laboreal/802 ; DOI : https://doi.org/10.4000/laboreal.802

Este documento foi criado de forma automática no dia 24 setembro 2020.

\section{cc) (7) (5)}

Laboreal está licenciado com uma Licença Creative Commons - Atribuição-NãoComercial 4.0 Internacional. 


\section{A aptidão profissional segundo J.-M. Lahy}

La aptitud profesional según J.-M. Lahy

L'aptitude professionnelle selon J.-M. Lahy

The occupational skill according to J.-M. Lahy

Marcel Turbiaux

Tradução : João Viana Jorge

\section{REFERÊNCIA}

Comentário do texto de J.-M. Lahy, « Qu'est-ce qu'une aptitude professionnelle ? - O que é uma aptidão profissional?» $3^{\mathrm{a}}$ conferência internacional de psicotécnica, Milan, 2-4 Outubro 1922.

\section{NOTA DO EDITOR}

http://dx.doi.org/10.15667/laborealxiii0117mt

Manuscrito recebido em: dezembro/2016

Aceite após peritagem: abril/2017

1 A aptidão, noção chave da orientação profissional, tal como da seleção profissional, foi objeto de numerosos debates no quadro do nascimento e do desenvolvimento da psicotécnica. Desde 1919, uma revista, L'orientation professionnelle, foi fundada por Frédéric Ozil (1879-1967), criador de l’Ecole universelle em 1907. Em 1920, é lá que Julien Fontègne (1869-1945) constrói um «Reportório bibliográfico sobre a questão da orientação profissional da juventude» que inclui já 333 títulos, testemunhos da sua importância. O comentário do texto de J.-M. Lahy (1872-1942), «Qu'est-ce qu'une aptitude professionnelle? O que é uma aptidão profissional ?», cria a oportunidade 
para voltar aos debates que atravessaram a orientação profissional na primeira metade do século XX.

2 1. Quando publica esse texto Lahy chefia os trabalhos no laboratório de psicologia experimental da École pratique des hautes études estabelecida em 1898, no asilo de Villejuif, por Edouard Toulouse, médico chefe (1865-1947), onde tinha entrado como aluno em 1901. Toulouse tinha empreendido em 1895, um «Inquérito médicopsicológico sobre as relações entre a superioridade intelectual e a neuropatia». 0 seu primeiro trabalho foi sobre Emile Zola (1840-1902), o qual estudou por observação direta, exame clínico e emprego de técnicas experimentais (testes mentais). Ao apresentar o seu ensaio à Sociedade médico-psicológica em 1897, concluía recomendando o método que tinha seguido para estudar Zola, não apenas sobre a superioridade intelectual mas também «as condições da superioridade em todas as profissões inclusive nas profissões manuais». Com essa finalidade, em 1900, sugeriu ao ministério do Comércio um projeto de «laboratório de pesquisas biológicas e sociais» tendente, entre outras coisas, a organizar a seleção profissional. Esse projeto não alcançou a execução mas o laboratório de psicologia fisiológica recebeu uma subvenção e Toulouse viria a confiar o estudo da superioridade profissional nas (diversas) profissões a J.-M. Lahy. Este, desde 1903 ligar-se-á ao estudo de uma profissão completamente nova, a da dactilografia, procurando, segundo o método preconizado por Toulouse, as condições da superioridade profissional nessa profissão e posteriormente, em 1908 nos guarda-freios [1] e a psicofisiologia nos soldados atiradores de metralhadora em 1916.

3 Em 1913 ao fazer o balanço das suas pesquisas sobre as dactilógrafas utiliza o termo «aptidão que caracteriza como uma boa memória das frases concretas, uma tendência para a equivalência das duas mãos, uma sensibilidade táctil e muscular afinada, uma atenção sustentada» (p. 833). Em 1922, a propósito da orientação profissional, à qual tinha consagrado, em Genève, em 1920, o primeiro congresso de psicotécnica «aplicado à orientação profissional» para um intercâmbio de ideias sobre o tema das «aptidões inatas e aptidões adquiridas», por iniciativa do Instituto Jean-Jacques Rousseau, precisará o que entende por aptidões : «disposições naturais que se reconhecem por respostas motoras ou mentais, mensuráveis, face a determinados estímulos» e mais precisamente as aptidões profissionais, as disposições naturais assim definidas cujos valores são da mesma ordem dos que se reconhecem nos trabalhadores de elite».

Edouard Toulouse que, desde 1903 [²], em Le Journal, profetizava : «Virá um dia em que o concurso consistirá de um exame médico psicológico no qual as aptidões particulares serão cotadas, e nenhum pai de família pressionará a sua criança para um ofício ou uma profissão sem o ter feito examinar», retornará a esta questão em " Le petit journal » de 24 de Agosto de 1921 («La vocation»), admitindo : «o que importa é selecionar cada indivíduo segundo as suas verdadeiras aptidões [...] A aptidão real consiste num pequeno número de qualidades fisiológicas que permitem cumprir mais rápida e seguramente os atos de uma determinada profissão. E isso parece verdade para o torneiro como para o engenheiro que dirige uma fábrica » e em L'ère nouvelle de 27 de Fevereiro de 1921 ( L'orientation professionnelle »), afirmando: «A ciência é a única capaz de determinar com provas (...) rápidas as relações entre aptidões e determinados modos de reação no decurso de experiências convenientemente escolhidas», anunciando uma conferência do (seu) «colaborador Lahy que de há muito se especializou no estudo da orientação profissional». 
5 Lahy (1922) expande a ideia de «antes de completamente pesquisar as aptidões características de uma profissão e de as classificar por ordem de importância para saber quais definem a superioridade, é preciso conhecer todas as aptidões requeridas para bem cumprir a maior parte dos trabalhos executados pelo homem e determinar para cada aptidão a sua ordem de grandeza nos diferentes indivíduos».

6 Na sua intervenção no congresso de Milão, consagrado explicitamente à definição da noção de aptidão, Lahy retoma a definição que havia dado em Le bulletin médical no mesmo ano, aplicável à seleção profissional mas também à orientação profissional. De facto, a intervenção de Lahy no Congresso de Milão é um pleito em defesa da sua conceção de aptidão profissional e da sua determinação, que defenderá ou precisará em diversos escritos e que tinha aplicado e viria a aplicar nas suas pesquisas e na sua crítica do «Sistema Taylor» [3].

7 2. A exposição de Lahy longamente discutida. As discussões revelam as hesitações da época sobre a teoria das aptidões. Neste sentido, Claparède escrevia em 1923: «O problema das aptidões ainda está envolto na obscuridade».

8 L. Remy compara «aptidão» e "hábito» : «A aptidão é uma disposição natural para efetivar certos atos, depende de uma disposição inata; o hábito é uma disposição adquirida para executar um maior número de atos semelhantes. A aptidão tal como o hábito aumenta quantitativamente o rendimento mas a aptidão acrescenta-lhe a qualidade. A possibilidade de aperfeiçoamento depende das faculdades intelectuais. Há portanto tantos grupos de aptidões quantos os de faculdades intelectuais, quer dizer que existem aptidões dos centros intelectuais superiores, aptidões dos centros de memória e aptidões sensoriais. Não podem medir-se estas diferentes aptidões e por conseguinte medir a inteligência das crianças. A escola deve contribuir para a organização da orientação profissional. Fornece as informações da psicologia e da pedagogia experimentais recolhidas no decurso dos exercícios escolares».

9 Segundo o mesmo "as aptidões intelectuais superiores têm uma importância considerável nas aptidões para os diversos ofícios, dado que qualquer ato, qualquer que seja a sua natureza, necessita da intervenção dos centros intelectuais superiores que regulam a execução dos movimentos [...] Os melhores órgãos sensoriais nem sempre correspondem aos melhores centros intelectuais superiores. É pois preciso ter em conta não apenas a quantidade mas também a qualidade dos estímulos recolhidos no mundo exterior».

Eugenio Rignano (1870-1930) pensa que a psicotécnica se ocupou até ao presente, demasiado exclusivamente das aptidões intelectuais e negligenciou as disposições afetivas.

11 Hugo Heinis (1883-1967), do gabinete de orientação experimental do Institut JeanJacques Rousseau criado em 1918, a propósito do conceito de inteligência geral, é de opinião que não há um mas vários tipos de inteligência. Admite a inteligência geral como capacidade de adaptação a condições novas se se considerar a inteligência no sentido lato. Em todas as suas experiências, que ultrapassam o milhar, nunca encontrou um indivíduo que fosse bom em todos os aspetos. Admite que «o homem não possui essa inteligência geral; o que temos é uma inteligência parcial. Portanto, do ponto de vista da psicologia aplicada [...] mais valia procurar localizar essa inteligência parcial em cada ofício do que ater-se a problemas excessivamente genéricos». 
12 Arthur Guillaume Christiaens (1860-1937), director do Office intercommunal d'orientation professionnelle de Bruxelles, aberto desde 1910, acha, pelo contrário, aceitável a definição de aptidão dada por Lahy: «A aptidão é o resultado da influência dos estímulos do meio nos elementos nervosos, cuja qualidade depende da hereditariedade. Como as condições muito variadas da vida profissional não podem ser reproduzidas à vontade no momento do exame, tornou-se necessário recorrer a testes para as substituir».

13 Edouard Claparède (1873-1940), fundador, em 1912, do Institut Jean-Jacques Rousseau, presidente da Association internationale de psychotechnique, do qual J.-M. Lahy era secretário geral permanente, admite que não é possível separar, na prática, a aptidão adquirida e a aptidão inata e insiste na necessidade de um entendimento sobre a escolha dos testes.

Gerard Anton Marie van Wayenburg, professor de psicologia da criança na universidade e diretor do laboratório psicotécnico da cidade de Amsterdão, propõe a sua definição de aptidão : a aptidão é um complexo de atos fisiológicos e psicológicos coordenados por uma finalidade. Algumas aptidões podem desenvolver-se mais ou menos tardiamente; por isso é necessário saber quais delas podem desenvolver-se mais tarde.

Otto Lipmann [4] (1880-1933), Director do Instituto de psicologia aplicada de Berlin e director do Zeitschriftfürangewandte Psychologie, considera que, na questão da inteligência geral se deveriam ter em conta duas questões em separado: Existe uma inteligência geral ? Como pode reconhecer-se a inteligência geral? E fornece a resposta a essas duas questões:

16 A inteligência geral não existe no sentido de que uma pessoa que compreende bem e prontamente as questões intelectuais é igualmente inteligente quando se trata de as adaptar às coisas ou às pessoas ou de as aplicar aos problemas técnicos. Trata-se pois de dois tipos diferentes de inteligência mas esta diferença tem um significado mais teórico que prático porque nas diversas profissões que são examinadas para a escolha de uma delas não se procura no início senão uma dessas inteligências que é calculada como uma inteligência geral.

Para estabelecer o grau dessa inteligência geral, uma prova (teste) não é suficiente, é necessária pelo menos uma série de provas do tipo das de Binet-Simon ou como as do Army test américain [5]. Retém todavia que um dos melhores meios para estabelecer essa inteligência é a observação, a qual permite não apenas observar um maior número de características na pessoa examinada mas também uma ideia mais justa da sua personalidade ; a observação que permite não somente estudar o seu comportamento natural mas também ver como se comporta perante a obrigação de prestar uma prova. A orientação profissional pode apoiar-se nestas observações mas a seleção deve apoiarse em particularidades mais detalhadas.

18 Claparède acrescenta uma outra questão à de Lipmann: qual é a influência da inteligência geral na profissão? Refere-se aos trabalhos de Hugo Münsterberg (1863-1916) e de outros que aplicaram testes a estudantes e estes ultrapassaram os outros sujeitos de diversas categorias, o que prova o valor da inteligência geral. Consequentemente convirá estabelecer para quais profissões a inteligência geral é mais útil e aquelas em que o é menos. 
19 Por fim, A. J. Petitpierre, director da escola profissional de Lausanne, considera o termo inteligência geral demasiado vago. Considera que as aptidões profissionais devem ser definidas conforme as profissões nas quais distingue três grupos: aquelas para as quais as aptidões intelectuais estão em primeiro lugar, aquelas em que nesse primeiro lugar estão as aptidões manuais ; as profissões para as quais é necessário um equilíbrio dos dois tipos de aptidões.

20 3. Entretanto em 1931, Franziska Baumgarten (1889-1970), faz notar, a propósito da definição de Lahy: «Por muito interessante que seja esta definição, contém a necessidade de rendimento que ultrapassa a média. Não se pode considerá-la suscetível de aplicações práticas por que os rendimentos elevados só se encontram minoritariamente em todas as profissões. A "aptidão profissional», como todas as aptidões, não deve ser entendida como uma disposição definida de alto nível, mas como uma disposição que pode encontrar-se em graus diversos (grande, pequena, média)» (p. 17-18).

21 Maurice Reuchlin (1920-2015), é ainda mais severo. Criticando (1954, p. 374) «a extraordinária vitalidade da falsa assimilação do resultado do teste com uma aptidão congénita», escreve : «Encontra-se esta assimilação [...] em J.-M. Lahy [...] Lahy está muito próximo de se encarcerar na tautologia [...] dado que após ter definido as aptidões como disposições naturais que se reconhecem pelas respostas motoras ou mentais - mensuráveis - a estímulos definidos, define o teste [...] como «uma prova do exame psicológico que permite apreciar certa aptidão pela medida dos resultados fornecidos pelo sujeito». Tal definição é suscetível de criar uma ambiguidade visto que a aptidão é apresentada simultaneamente como sendo «disposição natural» e «reconhecível nas respostas motoras ou mentais». De que meio dispomos para determinar a parte da disposição natural nas respostas medidas ?».

Entretanto Pierre Naville (1904-1993) criticava a definição de aptidão como «disposição natural» e definia a aptidão profissional como «um produto dialético, o resultado de interações entre o meio económico social [...] e os organismos individuais, entre as formas biológicas e sociais dos agrupamentos humanos. Não se trata senão de uma forma especial de adaptação. Piéron (1945), para quem a aptidão era a «condição congénita de uma certa modalidade de eficiência», responder-lhe-á precisando a distinção que, segundo ele, deve ser feita entre a aptidão "disposição nativa» e capacidade «resultado adquirido pelo exercício».

Assim, como o resume Antoine Léon (1921-1998), "passou-se de uma espécie de fatalismo da hereditariedade apoiada na noção de disposição natural a uma espécie de fatalismo do meio, ligado à ideia de diferenças culturais irreversíveis» (1980, p. 168). conduzir-nos ao esquecimento de que a análise dessa tensão mantém-se ainda como o maior desafio do trabalho dos investigadores e dos profissionais da orientação. 


\section{BIBLIOGRAFIA}

Baumgarten, F. (1931). Les examens d'aptitude professionnelle, Paris : Dunod.

Binet, A. (1910). Avant-propos : bilan de l'année 1910, L'année psychologique, 17, 1, V-XI.

Claparède, E. (1923). Comment diagnostiquer les aptitudes chez les écoliers. Paris : Flammarion.

Fontègne, J. (1920). Répertoire bibliographique sur la question d'orientation professionnelle de la jeunesse, Bulletin de l'Association française pour la lutte contre le chômage, 38-39, 45-62.

Lahy, J.-M. (1913). Les conditions psycho-physiologiques de l'aptitude au travail dactylographique, Journal de physiologie et de pathologie générale, 4, 826-834.

Lahy, J.-M. (1922). La psychologie expérimentale base de l'orientation professionnelle, Le bulletin médical, 24-27 mai, 438-441.

Lahy, J.-M. (1922). La sélection psycho-physiologique des travailleurs, Bulletin mensuel de la Ligue d'hygiène mentale, 1-2, 24-27.

Léon, A. (1980). Introduction à l'histoire des faits éducatifs. Paris : Presses Universitaires de France.

Lipmann, O. (1912). The school in the service of vocational study, British journal or psychology, XII, 4, 337-351.

Naville, P. (1945). Théorie de l'orientation professionnelle. Paris : Gallimard.

Piéron, H. (1912). Le domaine psychologique, L'année psychologique, 1, 1-26. https://doi.org/ 10.3406/psy.1912.3872

Piéron, H. (1914). Une œuvre psychologique de guerre : l'examen des aviateurs, L'année psychologique, 21, 237-252. https://doi.org/10.3406/psy.1914.8022

Piéron, H. (1945). La notion d'aptitude à propos d'une théorie de l'orientation professionnelle. Bulletin de l'Institut National d'Orientation Professionnelle,11-12, 169-175.

Reuchlin, M. (1954). Le problème théorique de la connaissance des aptitudes, Traité de psychologie applique, t. III, 371-394. Paris : Presses Universitaires de France.

Yoakum, C. S. \& Yerkes, R. M. (1920). Army mental tests. New York: Henry Holt et Cie. https:// doi.org/10.1037/11054-000

\section{NOTAS}

1. Piéron (1912, p. 15) Criticará rapidamente esta noção de superioridade, «conceito de valor» (que) não deve ter lugar em Ciência [...] É o nosso estado social que nos faz apreciar mais esta ou aquela aptidão».

2. Identicamente, Alfred Binet (1910) esperava publicar em 1912, um estudo sobre a «diversidade das aptidões das crianças» acentuando o imenso interesse que haveria em fazer saber a cada um o seu valor e a profissão à qual a sua natureza o destinava». Disso o impediu a sua morte em 1911.

3. No próximo número de Laboreal figurará a introdução comentada por J.-M. Lahy da sua obra sobre o taylorismo vinda a lume em 1916.

4. Lipmann (1912) já se tinha pronunciado longamente sobre a noção de aptidão.

5. Testes utilizados em 1917-1918 para recrutamento no exército americano (Yoakum, C. S. \& Yerkes, R. M. 1920). 


\section{AUTORES}

\section{MARCEL TURBIAUX}

Groupe de Recherche et d'Etude sur l'Histoire du Travail et de l'Orientation (GRESHTO)

Grupo de Pesquisa e de Estudo da História do Trabalho e da Orientação (GRESHTO)

Centre de Recherche sur le Travail et le Développement (CRTD)

Centro de Pesquisa sobre o Trabalho e o Desenvolvimento

Conservatoire National des Arts et Métiers (CNAM)

Conservatório Nacional das Artes e Ofícios (CNAM)

41, Rue Gay Lussac 75005, Paris, France

mturbiau@club-internet.fr 